\title{
Psychosocial distress and the preferred method of delivery of mind-body interventions among patients with head-and-neck cancer
}

This article was published in the following Dove Press journal: Patient Related Outcome Measures

\author{
Pinky Budhrani-Shani ${ }^{1,2}$ \\ Nicole G Chau ${ }^{3}$ \\ Donna L Berry 2,3 \\ 'Nelda C Stark College of Nursing, \\ Texas Woman's University, Houston, \\ TX, ${ }^{2}$ Phyllis F Cantor Center for \\ Research in Nursing and Patient Care \\ Services, ${ }^{3}$ Department of Medical \\ Oncology, Dana-Farber Cancer \\ Institute, Harvard Medical School, \\ Boston, MA, USA
}

\begin{abstract}
Objective: To describe the psychosocial distress of head-and-neck cancer patients at the completion of therapy and the interest in and the preferred method of delivery of mind-body interventions (MBIs) among head-and-neck cancer patients.
\end{abstract}

Materials and methods: A descriptive, cross-sectional design was used to measure sleep disturbance, depression, anxiety, and the interest in and the preference for MBIs using anonymous, self-report questionnaires among a convenience sample of 30 males at their 3-month follow-up. Questionnaires included the Pittsburgh Sleep Quality Index, Hospital Anxiety and Depression Scale, and the self-created Survey for Preferred Methods of MBI. Frequency distributions and descriptive statistics were used to describe the sample demographic and clinical characteristics. Results: The mean age of the sample was 59 years. Oral cancer (63\%) was the most common type of cancer. Nineteen participants $(63 \%, 90 \%$ CI $47 \%-78 \%)$ had some interest in MBIs. Of interested participants, 8 (42\%) preferred participating in MBIs alone, 10 (53\%) preferred participating in MBIs at homes, $10(53 \%)$ preferred participating in MBIs using a computer or mobile device, and 8 (42\%) preferred participating in MBIs after the diagnosis, but before treatment started. Mean depression, anxiety, and sleep disturbance scores were 8.25 (SD 2.93), 5.41 (SD 3.52), and 6.3 (SD 3.86), respectively. Results from the independent-samples $t$-test and Mann-Whitney $U$ tests revealed no significant differences in anxiety, depression, and sleep disturbance by MBI interest.

Conclusion: Asking about depression, anxiety, and sleep disturbances may help to identify head-and-neck cancer patients at risk for psychosocial distress. These findings suggest an interest in MBIs, but further research is warranted.

Keywords: depression, sleep, mind-body, intervention, head-and-neck cancer

\section{Introduction}

Head-and-neck cancer (HNC) is the ninth-most common cancer, comprising about 4\% of all cancers in the US. ${ }^{1,2}$ Advances in cancer screening, diagnosis, and treatment have substantially increased the number of HNC survivors, and with this have highlighted the importance of survivorship needs. Coping with the physical and emotional challenges of HNC and its treatment can lead to psychosocial distress among patients. ${ }^{3}$ HNC patients experience among the highest rates of major depressive disorders of all oncology patients, with prevalence rates as high as $46 \%$, which is particularly elevated compared to other oncology patients, in whom depression rates vary between $20 \%$ and $30 \% .{ }^{4}$ Tobacco and alcohol use are the most important risk factors for the majority of $\mathrm{HNC}$, which alone can also contribute to psychosocial distress, ${ }^{5}$ suggesting premorbid vulnerability among HNC patients. ${ }^{6}$ In addition, infection with human papillomavirus
Correspondence: Pinky Budhrani-Shani Nelda C Stark College of Nursing, Texas Woman's University, 6700 Fannin Street, Houston, TX 77030-2343, USA

Tel +l 7137942193

Email pbudhrani@twu.edu 
causes $>50 \%$ of oropharyngeal cancer, a subset of HNC that is increasing in incidence. ${ }^{1}$ Survivorship care is particularly important in patients with human papillomavirus-related HNC as these patients tend to be diagnosed at an earlier age and have a much better prognosis.

$\mathrm{HNC}$ has been identified as more emotionally traumatic than any other type of cancer, and HNC patients consistently rank among the top three cancers with the highest rates of suicide, after lung and stomach cancers. ${ }^{7,8}$ The increased levels of psychosocial distress and suicide may be associated with the negative functional impact HNC confers on eating, speaking, and communication, and the side effects of treatment, including pain, facial disfigurement, impaired swallowing function, and impaired speech. ${ }^{9-12}$ Furthermore, the treatment of HNC may have a negative impact on individual self-image, social functioning, and quality of life (QOL). , $^{3,9,13-15}$ Posttreatment, HNC patients describe difficulties in coping with the side effects of treatment and accessing supportive care when away from the hospital setting, leading to increased depression and anxiety during this period. ${ }^{16}$

At 12 months posttreatment, residual concerns among HNC survivors often include physical functioning, fatigue, xerostomia (dry mouth), and sticky saliva. ${ }^{17}$ Difficulty with saliva and swallowing can lead to decreased interest in social activities and relationships, which are predictive of anxiety in cancer survivors. ${ }^{18}$ Neilson et ${ }^{19}{ }^{19}$ found that anxiety levels were higher pretreatment and lower immediately following HNC treatment, but rose to near pretreatment levels more than a year after completion of cancer treatment. Sleep disturbances are also commonly experienced among HNC patients. ${ }^{20}$ In a longitudinal study of $270 \mathrm{HNC}$ patients before the start of radiation therapy, approximately $47 \%$ and $26 \%$ of patients reported moderate-severe and severe levels of sleep disturbances, respectively. ${ }^{20}$ HNC patients with sleep disturbances further reported increased daytime fatigue, concentration difficulties, and symptoms of depression. ${ }^{21}$ One year after the completion of treatment, sleep disturbances predicted survival among $\mathrm{HNC}$ patients. ${ }^{22} \mathrm{HNC}$ patients are at increased risk for sleep disturbances as a result of high rates of pain, depression, nicotine and alcohol use, obstructive sleep apnea, surgical alterations, and xerostomia. ${ }^{23,24}$ Factors affecting sleep include pain, xerostomia, depression, smoking, and drinking, suggesting that modifiable factors are associated with sleep disturbances among patients with HNC. ${ }^{24}$

The Institute of Medicine's report "From Cancer Patient to Cancer Survivor: Lost in Transition" emphasized the importance of interventional research to address the psychosocial consequences of cancer and its treatments, and that providing increased support during follow-up will likely lead to significant health-care cost savings. ${ }^{25}$ Exploration of complementary options, such as mind-body interventions, is common and increasingly popular among cancer survivors. According to the National Center for Complementary and Alternative Medicine, ${ }^{26}$ mind-body interventions include a variety of techniques designed to enhance the mind's capacity to affect bodily function and symptoms, and have the potential to target multiple physiological and psychological processes associated with cancer and its treatment. Mindfulness-based stress reduction (MBSR) is an evidence-based psychotherapy particularly well suited for the cancer population. ${ }^{27,28}$ The cancer experience is often described as a feeling of loss of control, uncertainty, constant change, and betrayal by one's body. MB interventions in cancer encourage people to accept difficult emotional experiences, embrace change, and reacquaint with their bodies. Past research on MBSR has been conducted primarily among breast and prostate cancer survivors. ${ }^{29,30}$ Both investigational and routine clinical psychosocial support for HNC patients are uncommon, precluding QOL benefits for these patients. ${ }^{16,31,32}$ Studies have suggested that HNC survivors are interested in interventions to improve their QOL, yet these studies have been completed among non-US populations, and currently one pilot study based in Australia is exploring MBSR as an intervention for HNC patients receiving radiation. ${ }^{33,34}$

Given the high prevalence of psychosocial distress among HNC patients, new approaches are desperately needed to improve both survivorship and QOL. ${ }^{33}$ Understanding the extent of psychosocial distress and preferences for delivery of mind-body intervention in HNC survivors is prerequisite to planning an intervention. ${ }^{35}$

\section{Materials and methods Design and sample}

An exploratory cross-sectional descriptive study was conducted in the ambulatory Head and Neck Oncology Clinic at the Dana-Farber Cancer Institute. Inclusion criteria were age $\geq 18$ years, diagnosis of locally advanced head or neck squamous cell carcinoma, within 3 months of completion of therapy (surgery, radiation therapy, or chemotherapy), and the ability to read and speak English at the eighth-grade level or above. Patients with a current diagnosis of a severe psychiatric disorder were excluded. This study was reviewed and approved by the Institutional Review Board of the DanaFarber Institute/Harvard Cancer Center and deemed exempt from further full institutional review-board review and given a waiver of written consent, as this was a voluntary, anonymous 
survey with full information provided. No protected health information was collected. The Head and Neck Oncology Clinic's program nurse identified potential participants as each arrived in the clinic setting. Eligible participants were provided with a paper survey packet upon check-in and prior to their scheduled 3-month follow-up clinic appointment.

\section{Procedure}

Between August 2014 and May 2015, eligible participants were provided with a paper survey packet and instructed to return the completed survey in a sealed envelope at the clinic or by mail in the preaddressed, postage-paid envelope.

\section{Measures}

Socioeconomic information was queried, including age, race/ ethnicity, religion, education, marital status, employment status, and income. Participants completed a medical history form for cancer diagnosis, date of diagnosis and treatment, treatment types, and additional treatment-related questions.

Anxiety and depression were measured using the Hospital Anxiety and Depression Scale (HADS). ${ }^{36}$ The HADS is a 14-item, self-report questionnaire measuring levels of anxiety and depression that have occurred over the past week in two separate seven-item subscales. Participants responded to items on a 4-point Likert scale, with possible subscale scores of $0-21$. The internal consistency in this study was 0.76 for the anxiety subscale and 0.82 for the depression subscale.

Sleep disturbance was measured using the Pittsburgh Sleep Quality Index (PSQI). ${ }^{37}$ This instrument contains 19 self-rated questions referring to respondents' sleep quality, sleep latency, sleep duration, habitual sleep efficiency, sleep disturbances, sleep medication use, and daytime dysfunction over the past month. The 19 self-rated questions produce seven component scores, scored on 4-point response options, which are summed for a global PSQI score. A global PSQI score >5 is associated with worse sleep quality. The overall reliability coefficient for the global PSQI was 0.56 for this study.

The survey for preferred method of mind-body intervention consisted of two sections with a total of 11 questions and took $<5$ minutes to complete. The first section consisted of investigator-designed questions assessing the preference for MBSR participation. The first question of this section assessed participant interest in MBSR. Respondents selected a number from 1 to 5 , with 1 being not interested and 5 being extremely interested. The second section consisted of questions from the 2012 national health interview survey questionnaire on adult alternative health/complementary and alternative medicine ${ }^{38}$ assessing any prior or current use of mind-body therapies.

\section{Data analysis}

SPSS version 22.0 was utilized for all data entry, management, and analysis for this study. Frequency distributions and descriptive statistics were used to describe demographic and clinical characteristics. Continuous variables and categorical variables were analyzed using descriptive statistics. Independent-sample $t$-tests and nonparametric Mann-Whitney $U$ tests were used to determine if anxiety, depression, and sleep disturbance scores differed significantly by MBSR interest. Anxiety and depression scores were grouped as "no anxiety" and "no depression" for scores 0-7 and "some anxiety" and "some depression" for scores $\geq 8$ on the HADS. Sleep disturbances scores were grouped as "no sleep disturbances" for scores $<5$ and "some sleep disturbances" for scores $\geq 5$ on the PSQI. Cross tabulations using Pearson's $\chi^{2}$ and Cramer's $V$ were used to examine the relationship between treatment type and MBSR interest. An $\alpha$-level of 0.05 was used to determine the statistical significance.

\section{Results \\ Sample demographics}

Approximately five completed questionnaires per month were returned, for a total of 31 questionnaires over the collection period of 6 months. One questionnaire was completed by a woman. For consistency, the data for this study were analyzed on the 30 men who completed the surveys. Table 1 lists the demographic and clinical characteristics of all participants. The ethnicity of the sample consisted of 22 (73\%) non-Hispanics, $6(20 \%)$ Hispanics, and 2 (7\%) who did not provide this information. The mean age was 59 years (51-69 years). The most common type of cancer was oral cancer $(63 \%)$, and the most common type of treatment was a combination of radiation and chemotherapy $(80 \%)$.

\section{Symptom assessment}

Mean depression, anxiety, and sleep disturbance scores were 8.25 (SD 2.93), 5.41 (SD 3.52), and 6.3 (SD 3.86), respectively. Percentages of the sample reporting some level of depression, anxiety, and sleep disturbances are presented in Table 2.

\section{MBSR interest and preference}

Of all participants, $63 \%$ of the sample was interested in MBSR. Preferences for setting, location, initiation of 
Table I Demographics and clinical characteristics of participants $(n=30)$

\begin{tabular}{|c|c|c|c|}
\hline \multicolumn{2}{|c|}{ Demographics/clinical characteristics } & \multirow[t]{2}{*}{$\mathbf{n}$} & \multirow[t]{2}{*}{$\%$} \\
\hline \multicolumn{2}{|l|}{ Race } & & \\
\hline & White & 27 & 90 \\
\hline & Black or African-American & 0 & \\
\hline & Asian & I & 3.3 \\
\hline & Other & 1 & 3.3 \\
\hline & More than one race & I & 3.3 \\
\hline
\end{tabular}

Ethnicity

$\begin{array}{lll}\text { Non-Hispanic } & 22 & 73.3 \\ \text { Hispanic or Latino } & 6 & 20 \\ \text { Total } & 28 & 93.3\end{array}$

Marital status

Married $\quad 28 \quad 93.3$

Work status

Single

26.7

Disability

Full time

Retired

Unemployed

Other

Annual income (US\$)

25,000-74,999

$75,000-99,999$

$>100,000$

Missing

Type of cancer

Larynx

Oral

Pharynx

Tonsils

Missing

Treatment type

$\begin{array}{lll}\begin{array}{l}\text { Surgery, radiation, and } \\ \text { chemotherapy }\end{array} & 6 & 20 \\ \begin{array}{l}\text { Only radiation and } \\ \text { chemotherapy }\end{array} & 24 & 80\end{array}$

Difficulty swallowing

No

Yes

$14 \quad 46.7$

$16 \quad 53.3$

Feeding tube

$\begin{array}{lll}\text { No } & 26 & 86.7 \\ \text { Yes } & 4 & 13.3\end{array}$

Note: Frequencies not summing to 30 and percentages not summing to 100 indicate missing data.

program, and previous use of relaxation techniques of those that were interested are presented in Table 3.

\section{Relationships among anxiety, depression, and sleep disturbances by MBSR interest}

Results from the independent-sample $t$-test and nonparametric Mann-Whitney $U$ tests revealed no significant differences for anxiety, depression, or sleep disturbance
Table 2 Symptoms among participants $(n=30)$

\begin{tabular}{lll}
\hline Symptoms & $\mathbf{n}$ & $\%$ \\
\hline Depression & 15 & 50 \\
$\quad$ None & 15 & 50 \\
Some & & \\
Anxiety & 18 & 60 \\
$\quad$ None & 12 & 40 \\
$\quad$ Some & & \\
Sleep disturbances & 14 & 46.7 \\
None & 15 & 50 \\
Some & 1 & 3.3 \\
Missing & 15
\end{tabular}

Notes: Frequencies not summing to 30 and percentages not summing to 100 indicate missing data. No anxiety and no depression included scores $0-7$, and some anxiety and some depression included scores $\geq 8$ on the HADS; no sleep disturbances included scores $<5$, and some sleep disturbances included scores $>5$ on the PSQI.

Abbreviations: HADS, Hospital Anxiety and Depression Scale; PSQI, Pittsburgh Sleep Quality Index.

Table 3 MBSR variables among participants

\begin{tabular}{|c|c|c|}
\hline MBSR variables & $\mathbf{n}$ & $\%$ \\
\hline \multicolumn{3}{|l|}{ Interest } \\
\hline None & II & 36.7 \\
\hline Some & 19 & 63.3 \\
\hline \multicolumn{3}{|l|}{ Setting } \\
\hline Alone & 8 & 42.1 \\
\hline With other cancer survivors & II & 57.9 \\
\hline No preference & 0 & \\
\hline \multicolumn{3}{|l|}{ Location } \\
\hline At home & 10 & 52.6 \\
\hline In a hospital/clinical setting & 6 & 31.6 \\
\hline No preference & 1 & 5.3 \\
\hline \multicolumn{3}{|l|}{ Initiation of program } \\
\hline After diagnosis, but before treatment starts & 8 & 42.1 \\
\hline During treatment & 6 & 31.6 \\
\hline $3-6$ months after treatment & 4 & 21.1 \\
\hline $6-12$ months after treatment & I & 5.2 \\
\hline \multicolumn{3}{|l|}{ Use prior to diagnosis of meditation, guided } \\
\hline \multicolumn{3}{|l|}{ imagery, or progressive relaxation } \\
\hline Yes & 6 & 20 \\
\hline No & 24 & 80 \\
\hline \multicolumn{3}{|l|}{ Prior to diagnosis of mantra meditation } \\
\hline Yes & 2 & 6.7 \\
\hline No & 28 & 93.3 \\
\hline \multicolumn{3}{|l|}{ Prior to diagnosis of mindfulness } \\
\hline \multicolumn{3}{|l|}{ meditation } \\
\hline Yes & 2 & 6.7 \\
\hline No & 8 & 26.7 \\
\hline Don't know & 19 & 63.3 \\
\hline Missing & I & 3.3 \\
\hline \multicolumn{3}{|l|}{ Prior to diagnosis of spiritual meditation } \\
\hline Yes & 4 & 13.3 \\
\hline No & 26 & 86.7 \\
\hline \multicolumn{3}{|l|}{ Prior to diagnosis of guided imagery } \\
\hline Yes & 3 & 13.3 \\
\hline No & 27 & 90 \\
\hline
\end{tabular}

Notes: Frequencies not summing to 30 and percentages not summing to 100 indicate missing data; "some" interest based on a score of $\geq 2$.

Abbreviation: MBSR, mindfulness-based stress reduction. 
by MBSR interest $(P>0.05)$. Exact $P$-values are shown in Table 4.

\section{Relationship between treatment/ symptom variables and preference for MBSR}

Differences in MBSR interest based on the type of HNC, the type of treatment, and the presence of depression, anxiety, and sleep disturbances are seen in Table 5. A significant relationship was found between the type of treatment and MBSR interest $\left(\chi_{1}^{2}=7.03\right.$, Cramer's $\left.V=0.48 ; P=0.008\right)$. A greater

Table 4 Relationships among anxiety, depression, and sleep disturbances by MBSR interest $(n=30)$

\begin{tabular}{llllll}
\hline Symptoms & $\mathbf{n}$ & $\overline{\mathbf{x}}$ & $\mathbf{S D}$ & $\boldsymbol{t}$ & $\boldsymbol{P}$ \\
\hline Anxiety & & & & 0.35 & 0.73 \\
$\quad$ No interest & II & 7.45 & 3.83 & & \\
$\quad$ Some interest & 19 & 7 & 3.22 & & \\
$\quad \begin{array}{l}\text { Depression } \\
\quad \text { No interest }\end{array}$ & 11 & 6.09 & 3.15 & & \\
$\quad$ Some interest & 19 & 7.63 & 3.17 & & \\
$\quad$ Sleep disturbances & & & & -0.22 & 0.829 \\
$\quad$ No interest & 11 & 11 & 5.59 & & \\
$\quad$ Some interest & 19 & 11.39 & 4.02 & & \\
\hline
\end{tabular}

Abbreviation: MBSR, mindfulness-based stress reduction. proportion of participants who received only radiation and chemotherapy expressed some MBSR interest (94.7\%) compared to participants who showed no interest (54.5\%). In contrast, a greater proportion of participants who received all three treatments expressed no MBSR interest (45.5\%) compared to participants who had some interest (5.3\%).

\section{Discussion}

To our knowledge, this study is the first to explore the prevalence of psychosocial distress among HNC patients combined with the preference for mind-body interventions. First, we found high rates of self-reported sleep disturbance, anxiety, and depression symptoms among HNC patients following completion of therapy. Second, our findings with minimal missing responses suggest that $\mathrm{HNC}$ patients have a preference for mind-body interventions initiated at home, with other cancer survivors, and early in the treatment trajectory. Interestingly, all but one of the returned surveys were from men. We have no exact record of the number of surveys actually distributed by the program nurse. The ratio of men to women treated in the clinic is 3:1, and low female participation was expected. Previous studies among the HNC population have reported higher male incidence and participation. ${ }^{39}$

Table 5 Cross-tabulation of relationships among clinical variables, symptoms, and MBSR interest $(n=30)$

\begin{tabular}{|c|c|c|c|c|c|c|c|}
\hline \multirow[t]{2}{*}{ Clinical variables/symptoms } & \multicolumn{2}{|c|}{ No interest } & \multicolumn{2}{|c|}{ Some interest } & \multirow[t]{2}{*}{$\chi^{2}$} & \multirow[t]{2}{*}{$P$} & \multirow[t]{2}{*}{ Cramer's V } \\
\hline & $\bar{n}$ & $\%$ & $\bar{n}$ & $\%$ & & & \\
\hline HNC type & & & & & 2.23 & 0.526 & 0.277 \\
\hline Larynx & 0 & & 3 & 15.8 & & & \\
\hline Oral & 8 & 80 & 11 & 57.9 & & & \\
\hline Pharynx & 1 & 10 & 3 & 15.8 & & & \\
\hline Tonsils & I & 10 & 2 & 10.5 & & & \\
\hline Feeding tube & & & & & 2.67 & 0.102 & 0.298 \\
\hline No & 11 & 100 & 15 & 78.9 & & & \\
\hline Yes & 0 & & 4 & 21.1 & & & \\
\hline Difficulty swallowing & & & & & 0.01 & 0.919 & 0.018 \\
\hline No & 5 & 45.5 & 9 & 47.4 & & & \\
\hline Yes & 6 & 54.5 & 10 & 52.6 & & & \\
\hline Anxiety & & & & & 0.22 & 00.643 & 0.085 \\
\hline None & 6 & 54.5 & 12 & 63.2 & & & \\
\hline Some & 5 & 45.5 & 7 & 36.8 & & & \\
\hline Depression & & & & & 0.14 & 0.705 & 0.069 \\
\hline None & 6 & 54.5 & 9 & 47.4 & & & \\
\hline Some & 5 & 45.5 & 10 & 52.6 & & & \\
\hline Sleep disturbances & & & & & 0.28 & 0.597 & 0.098 \\
\hline None & 6 & 54.5 & 8 & 44.4 & & & \\
\hline Some & 5 & 45.5 & 10 & 55.6 & & & \\
\hline Treatment & & & & & 7.03 & 0.008 & 0.484 \\
\hline Surgery, radiation, and chemotherapy & 5 & 45.5 & I & 5.3 & & & \\
\hline Only radiation and chemotherapy & 6 & 54.5 & 18 & 94.7 & & & \\
\hline
\end{tabular}

Abbreviations: MBSR, mindfulness-based stress reduction; HNC, head-and-neck cancer. 
Approximately 50\% of the sample reported some level of depression, anxiety, and sleep disturbances. This is in keeping with previous studies that have reported incidence rates of $15 \%-50 \%$ for major depressive disorder among $\mathrm{HNC}$ patients and clinically significant anxiety. ${ }^{40,41} \mathrm{~A}$ longitudinal study among HNC patients found that depression increased between the start of radiotherapy and up to 3 weeks following, while anxiety increased between 3 weeks and 18 months postradiotherapy, with lower QOL related to increased depression and anxiety. ${ }^{19}$ Furthermore, a review of depression among $\mathrm{HNC}$ patients found that psychosocial distress was associated with lower QOL, reduced immunity, prolonged hospital stays, and decreased self-care abilities. ${ }^{40}$

Key findings of this study suggest that men with $\mathrm{HNC}$ are interested in MBSR after their diagnosis - but before treatment starts or during treatment - and a significant difference was found between the type of treatment and the interest in MBSR. This is noteworthy because past research on MBSR has focused primarily on providing the intervention after the completion of treatment during the survivorship period. ${ }^{30,42,43}$ Pollard et $\mathrm{al}^{39}$ found that $\mathrm{HNC}$ participants were adherent to the IMBSR program and compliant with a home practice requirement, despite the increasing toxicity burden faced by patients during the course of radiation therapy. In addition, past research findings have suggested that patients receiving treatment while participating in MBSR experience significant improvements in QOL, depression, anxiety, and mood (chemotherapy and/or radiation), and psychosocial coping, helplessness, hostility, and emotional control (radiation only)..$^{44,45}$

A single-arm study to address the challenges faced by HNC patients during active treatment using an individualized MBSR intervention was completed by Pollard et al. ${ }^{39}$ Individualized MBSR was delivered in seven 90-minute sessions administered one on one by clinical psychologists to $19 \mathrm{HNC}$ patients. Sessions were run concurrently with the patient's radiotherapy treatment on a weekly basis. Increased levels of postintervention mindfulness were associated with decreased postintervention psychological distress, including depression and anxiety, and increased QOL, social wellbeing, and emotional well-being. ${ }^{39}$ These results indicated that an individualized MBSR program could be used successfully with HNC patients undergoing curative treatment and warrant further testing in randomized trials.

\section{Strengths and limitations}

Given our single-gender results from a comprehensive cancer center with limited racial diversity, these findings cannot be generalized to women with $\mathrm{HNC}$ or to more racially diverse groups or community settings. Second, history and current use of tobacco and alcohol were not collected. Third, participants who were interested in reporting outcomes and preferences may have been more likely to return the survey; this could have resulted in selection bias. Finally, an untested instrument was utilized for collecting intervention preference data and may not have assessed participants' preference reliably. The results of this study suggested that patients with $\mathrm{HNC}$ are interested in interventions provided at home. More widespread access to mind-body interventions targeting patients with cancer has been challenged by economic, geographic, and time barriers ${ }^{46}$ Common barriers to in-person group classes might be overcome with Internet-based delivery of intervention, offering an alternative for some individuals that may significantly increase access and adherence.

\section{Implications for research and practice}

Based on the previous research and clinical practice, many patients with psychosocial distress do not want to be referred to psychological care, and thus, MBSR interventions could play a critical role and serve as a bridge to professional services. ${ }^{47,48}$ The findings of this research study can be used to plan optimal locations and timing of MBSR as an intervention to address the psychosocial needs and QOL of HNC patients. Our findings suggest that future research evaluating MBSR interventions may be best implemented prior to or during curative definitive therapy, rather than following treatment completion. The majority of patients in our study preferred to participate in MBSR with other cancer survivors, and there is also growing public interest in mindfulness training online and using smartphones. As patients gain increased access to computers and mobile devices, we believe that studying the possibilities and effects of extending cancer care beyond conventional face-to-face care through mobile devices is warranted. In a systematic review of 10 studies delivering MB therapy through technological platforms, Fish et $\mathrm{a}^{28}$ reported that anxiety, depression, and stress were reduced in a number of studies. The effect sizes of online interventions were comparable to the effect sizes of face-to-face mindfulness interventions on anxiety and depression scores. ${ }^{49-51}$

In addition, assessments of distress should be incorporated as part of survivorship care. The National Comprehensive Cancer Network Distress Thermometer provides a tool to self-identify distress level from 0 to 10 , with 10 being an extreme level of distress. ${ }^{52}$ As emotional side effects of cancer are not often discussed, this tool may make it easier for patients to disclose emotional concerns related to diagnosis and treatment. Adherence to appropriate screening 
protocols and identification of distress have led to an $18 \%$ decrease in emergency department visits and a $19 \%$ decrease in hospitalizations in a 2-month period following screening. . $^{53}$ The incorporation of distress screening may ultimately lead to improved psychosocial and physical health outcomes. Finally, while the majority of $\mathrm{HNC}$ cases occur in men, ${ }^{54}$ future studies incorporating larger sample sizes should assure appropriate sex representation.

\section{Conclusion}

In conclusion, this study was an important preliminary step, suggesting that men with $\mathrm{HNC}$ commonly experience psychosocial distress, and further suggests that they are interested in participating in an MBSR program. Our participants expressed interest in participating in MBSR with other cancer survivors at a home location, indicating that interactive online applications may be preferred methods of delivery. Our findings also suggest preferences for MBSR interventions to begin prior to or during treatment, rather than following treatment completion, and the optimal timing of MBSR should be studied further.

\section{Acknowledgments}

The authors would like to acknowledge Robert Haddad, MD, Laura Ma, RN, and Holly Lopes, RN, who provided support in patient identification and distribution of questionnaires. Funding for this study was supplied by the Mittelman Family Foundation.

\section{Disclosure}

The authors report no conflicts of interest in this work.

\section{References}

1. National Cancer Institute. Head and neck cancer: patient version. 2014 Available from: http://www.cancer.gov/cancertopics/types/head-andneck. Accessed January 13, 2018.

2. Siegel RL, Miller KD, Jemal A. Cancer statistics, 2017. CA Cancer J Clin. 2017;67(1):7-30.

3. Funk GF, Karnell LH, Christensen AJ. Long-term health-related quality of life in survivors of head and neck cancer. Arch Otolaryngol Head Neck Surg. 2012;138(2):123-133.

4. Katz MR, Kopek N, Waldron J, Devins GM, Tomlinson G. Screening for depression in head and neck cancer. Psychooncology. 2004;13(4):269-280.

5. US Institute of Medicine. State of the USA Health Indicators: Letter Report. Washington, DC: Institute of Medicine; 2009.

6. Luckett T, Britton B, Clover K, Rankin NM. Evidence for interventions to improve psychological outcomes in people with head and neck cancer: a systematic review of the literature. Support Care Cancer. 2011;19(7):871-881.

7. Misono S, Weiss NS, Fann JR, Redman M, Yueh B. Incidence of suicide in persons with cancer. J Clin Oncol. 2008;26(29):4731-4738.

8. Kendal WS. Suicide and cancer: a gender-comparative study. Ann Oncol. 2007;18(2):381-387.
9. Sherman AC Simonton S. Advances in quality of life research among head and neck cancer patients. Curr Oncol Rep. 2010;12(3): 208-215.

10. Fang FM, Tsai WL, Chien CY, Chiu HC, Wang CJ. Health-related quality of life outcome for oral cancer survivors after surgery and postoperative radiotherapy. Jpn J Clin Oncol. 2004;34(11):641-646.

11. Penner JL. Psychosocial care of patients with head and neck cancer. Semin Oncol Nurs. 2009;25(3):231-241.

12. Menvielle G, Luce D, Goldberg P, Leclerc A. Smoking, alcohol drinking, occupational exposures and social inequalities in hypopharyngeal and laryngeal cancer. Int J Epidemiol. 2004;33(4):799-806.

13. Rogers SN, Ahad SA, Murphy AP. A structured review and theme analysis of papers published on "quality of life" in head and neck cancer: 2000-2005. Oral Oncol. 2007;43(9):843-868.

14. Eades, Chasen MM, Bhargava R. Rehabilitation: long-term physical and functional changes following treatment. Semin Oncol Nurs. 2009;25(3):222-230.

15. Stuiver MM, van Wilgen CP, de Boer EM, et al. Impact of shoulder complaints after neck dissection on shoulder disability and quality of life. Otolaryngol Head Neck Surg. 2008;139(1):32-39.

16. Moore KA, Ford PJ, Farah CS. "I have quality of life . . . but . ..": exploring support needs important to quality of life in head and neck cancer. Eur J Oncol Nurs. 2014;18(2):192-200.

17. So WK, Chan RJ, Chan DN, et al. Quality-of-life among head and neck cancer survivors at one year after treatment: a systematic review. Eur $J$ Cancer. 2012;48(15):2391-2408.

18. Carlson LE, Waller A, Groff SL, Giese-Davis J, Bultz BD. What goes up does not always come down: patterns of distress, physical and psychosocial morbidity in people with cancer over a one year period. Psychooncology. 2013;22(1):168-176.

19. Neilson K, Pollard A, Boonzaier A, et al. A longitudinal study of distress (depression and anxiety) up to 18 months after radiotherapy for head and neck cancer. Psychooncology. 2013;22(8):1843-1848.

20. Gunn GB, Mendoza TR, Fuller CD, et al. High symptom burden prior to radiation therapy for head and neck cancer: a patient-reported outcomes study. Head Neck. 2013;35(10):1490-1498.

21. Havekes B, Kastelein F, van der Klaauw AA, et al. Head-and-neck paragangliomas are associated with sleep-related complaints, especially in the presence of carotid body tumors. Sleep Breath. 2012;16(2): $527-534$.

22. Osthus AA, Aarstad AK, Olofsson J, Aarstad HJ. Head and neck specific health related quality of life scores predict subsequent survival in successfully treated head and neck cancer patients: a prospective cohort study. Oral Oncol. 2011;47(10):974-979.

23. Savard J, Villa J, Ivers H, Simard S, Morin CM. Prevalence, natural course, and risk factors of insomnia comorbid with cancer over a 2-month period. J Clin Oncol. 2009;27(31):5233-5239.

24. Shuman AG, Terrell JE, Light E, et al. Predictors of poor sleep quality among head and neck cancer patients. Laryngoscope. 2010;120(6):1166-1172.

25. Hewitt M, Greenfield S, Stovall E, editors. From Cancer Patient to Cancer Survivor: Lost in Transition., Washington, DC: National Academies Press; 2005.

26. National Center for Complementary and Integrative Health. Complementary, alternative, or integrative health: what's in a name? 2008. Available from: https://nccih.nih.gov/health/integrative-health. Accessed January 13, 2018.

27. Carlson LE. Mindfulness-based interventions for physical conditions: a narrative review evaluating levels of evidence. ISRN Psychiatry. 2012;2012:651583.

28. Fish J, Brimson J, Lynch S. Mindfulness interventions delivered by technology without facilitator involvement: what research exists and what are the clinical outcomes? Mindfulness (NY). 2016;7(5):1011-1023.

29. Huang HP, He M, Wang HY, Zhou M. A meta-analysis of the benefits of mindfulness-based stress reduction (MBSR) on psychological function among breast cancer (BC) survivors. Breast Cancer. 2016;23(4):568-576. 
30. Lengacher CA, Reich RR2, Paterson CL, et al. Examination of broad symptom improvement resulting from mindfulness-based stress reduction in breast cancer survivors: a randomized controlled trial. J Clin Oncol. 2016;34(24):2827-2834.

31. Shiraz F, Rahtz E, Bhui K, Hutchison I, Korszun A. Quality of life, psychological wellbeing and treatment needs of trauma and head and neck cancer patients. Br J Oral Maxillofac Surg. 2014;52(6):513-517.

32. Lang H, France E, Williams B, Humphris G, Wells M. The psychological experience of living with head and neck cancer: a systematic review and meta-synthesis. Psychooncology. 2013;22(12):2648-2663.

33. Allison PJ, Edgar L, Nicolau B, Archer J, Black M, Hier M. Results of a feasibility study for a psycho-educational intervention in head and neck cancer. Psychooncology. 2004;13(7):482-485.

34. Couper J, Pollard A, Castle D, et al. Phase 1 pilot of a mindfulnessbased stress reduction intervention for head and neck cancer patients receiving treatment. 2014. Available from: https://www.beyondblue. org.au/about-us/research-projects/research-projects/Phase-one-pilotof-a-mindfulness-based-stress-reduction-intervention-for-head-andneck-cancer-patients. Accessed January 13, 2018.

35. Reich M, Leemans CR, Vermorken JB, et al. Best practices in the management of the psycho-oncologic aspects of head and neck cancer patients: recommendations from the European Head and Neck Cancer Society Make Sense Campaign. Ann Oncol. 2014;25(11):2115-2124.

36. Zigmond AS, Snaith RP. The Hospital Anxiety and Depression Scale. Acta Psychiatr Scand. 1983;67(6):361-370.

37. Buysse DJ, Reynolds CF 3rd, Monk TH, Berman SR, Kupfer DJ. The Pittsburgh Sleep Quality Index: a new instrument for psychiatric practice and research. Psychiatry Res. 1989;28(2):193-213.

38. National Institutes of Health. Adult complementary health practices questionnaire. 2012. Available from: https://nccih.nih.gov/research/ statistics/NHIS. Accessed February 21, 2018.

39. Pollard A, Burchell JL, Castle D, et al. Individualised mindfulnessbased stress reduction for head and neck cancer patients undergoing radiotherapy of curative intent: a descriptive pilot study. Eur J Cancer Care (Engl). 2017;26(2):1-11.

40. Lydiatt WM, Moran J, Burke WJ. A review of depression in the head and neck cancer patient. Clin Adv Hematol Oncol. 2009;7(6):397-403.

41. Howren MB, Christensen AJ, Karnell LH, Funk GF. Psychological factors associated with head and neck cancer treatment and survivorship: evidence and opportunities for behavioral medicine. J Consult Clin Psychol. 2013;81(2):299-317.

42. Johns SA, Von Ah D, Brown LF, et al. Randomized controlled pilot trial of mindfulness-based stress reduction for breast and colorectal cancer survivors: effects on cancer-related cognitive impairment. J Cancer Surviv. 2016;10(3):437-448.
43. Reich RR, Lengacher CA, Alinat CB, et al. Mindfulness-based stress reduction in post-treatment breast cancer patients: immediate and sustained effects across multiple symptom clusters. J Pain Symptom Manage. 2017;53(1):85-95.

44. Henderson VP, Clemow L, Massion AO, Hurley TG, Druker S, Hébert JR. The effects of mindfulness-based stress reduction on psychosocial outcomes and quality of life in early-stage breast cancer patients: a randomized trial. Breast Cancer Res Treat. 2012;131(1): 99-109.

45. Altschuler A, Rosenbaum E, Gordon P, Canales S, Avins AL. Audio recordings of mindfulness-based stress reduction training to improve cancer patients' mood and quality of life: a pilot feasibility study. Support Care Cancer. 2012;20(6):1291-1297.

46. Loh SY, Lee SY, Quek KF, Murray L. Barriers to participation in a randomized controlled trial of qigong exercises amongst cancer survivors: lessons learnt. Asian Pac J Cancer Prev. 2012;13(12): 6337-6342.

47. Jansen F, van Uden-Kraan CF, van Zwieten V, Witte BI, Verdonck-de Leeuw IM. Cancer survivors' perceived need for supportive care and their attitude towards self-management and eHealth. Support Care Cancer. 2015;23(6):1679-1688.

48. Lubberding S, van Uden-Kraan CF, Te Velde EA, Cuijpers P, Leemans CR, Verdonck-de Leeuw IM. Improving access to supportive cancer care through an eHealth application: a qualitative needs assessment among cancer survivors. J Clin Nurs. 2015;24(9-10): 1367-1379.

49. Fjorback LO, Arendt M, Ornbøl E, Fink P, Walach H. Mindfulnessbased stress reduction and mindfulness-based cognitive therapy: a systematic review of randomized controlled trials. Acta Psychiatr Scand. 2011;124(2):102-119.

50. Khoury B, Lecomte T, Fortin G, et al. Mindfulness-based therapy: a comprehensive meta-analysis. Clin Psychol Rev. 2013;33(6): 763-771.

51. Chiesa A, Calati R, Serretti A. Does mindfulness training improve cognitive abilities? A systematic review of neuropsychological findings. Clin Psychol Rev. 2011;31(3):449-464.

52. National Comprehensive Cancer Network. Managing stress and distress. 2017. Available from: https://www.nccn.org/patients/resources/ life_with_cancer/distress.aspx. Accessed January 13, 2018.

53. Zebrack B, Kayser K, Bybee D, et al. A practice-based evaluation of distress screening protocol adherence and medical service utilization. J Natl Compr Canc Netw. 2017;15(7):903-912.

54. Ridge JA, Mehra R, Lango MN, Galloway T. Head and neck tumors. 2016. Available from: http://www.cancernetwork.com/cancer-management/head-and-neck-tumors. Accessed January 13, 2018.

\section{Patient Related Outcome Measures}

\section{Publish your work in this journal}

Patient Related Outcome Measures is an international, peer-reviewed, open access journal focusing on treatment outcomes specifically relevant to patients. All aspects of patient care are addressed within the journal and practitioners from all disciplines are invited to submit their work as well as healthcare researchers and patient support groups.

\section{Dovepress}

The journal is included in PubMed. The manuscript management system is completely online and includes a very quick and fair peer-review system. Visit http://www.dovepress.com/testimonials.php to read real quotes from published authors. 